Volumen $16 n^{\circ} 12013$

\title{
Editorial
}

\section{Enfermero Especialista en Cuidados Médico-Quirúrgicos. El final de la especialidad que nunca existió.}

Era lógico que la Especialidad en Cuidados Médico-Quirúrgicos, tal como recogía el catálogo del Real Decreto 450/2005 de Especialidades de Enfermería no se desarrollara. Cuando se negociaron algunos contenidos de este RD, la Organización Colegial de Enfermería (OCE) y la Federación Española de Sociedades Científicas de Enfermería (FESCE), propusimos como nombre genérico para esta especialidad, Enfermero Especialista en Enfermería Clínica Avanzada, que no satisfacía las aspiraciones de ninguna de las sociedades representadas en la FESCE, pero dejaba las puertas abiertas a un posterior desarrollo, mediante las Áreas de Capacitación Específica, que la Ley de Ordenación de la Profesiones Sanitarias contemplaba. Se trataba de abrir la "puerta", y que luego la realidad asistencial, las necesidades de salud de la población o los avances científico-tecnológicos marcaran las áreas a desarrollar como especialidad dentro de la troncalidad.

Sin embargo, desde el Ministerio de Educación, no se permitió esa denominación y se impuso la conocida por todos: Enfermero Especialista en Cuidados Médico-Quirúrgicos. En aquel momento nos pareció que bueno...; por lo menos había salido el RD de Especialidades y ya se intentaría el desarrollo de las Áreas de Capacitación Específica (perfusión, nefrología, quirúrgicos, urgencias y críticos...). Lo más curioso de la elección de esta denominación es que era la repetición de una materia de los estudios de la Diplomatura de Enfermería, lo cual no era lógico, pues si algo justifica una especialización es conseguir competencias diferentes a las alcanzadas con el título generalista. No era necesaria una superespecialización para trabajar en las áreas médico-quirúrgica de la atención especializada, ni esa especialidad la justificaba ninguna necesidad de salud concreta.

No obstante, no hubo otra opción y el efecto a medio y largo plazo que tendría esta denominación fue perfectamente calculado, no fue el azar quién determinó la misma, fueron los mismos intereses espurios, que desde el Ministerio de Sanidad, impidieron durante muchos años que se desarrollaran las especialidades de enfermería del anterior real decreto. Quien esto suscribe terminó muy decepcionado con todo este proceso y abandoné voluntariamente todo tipo de representatividad relacionada con las especialidades de enfermería, primero por coherencia: no creía que todas las sociedades representadas en la FESCE tenían que ser especialidades; y segundo: intuía que no iba a haber nunca un consenso sobre el desarrollo del Enfermero Especialista en Cuidados Médico-Quirúrgicos. No hacía falta tener una capacidad visionaria especial para entender que se cumpliría un refrán muy de nuestra tierra "quien hizo la ley hizo la trampa". Poco a poco, todas las especialidades del catálogo del RD 450/2005, fueron desarrollando su Plan Formativo y en la convocatoria EIR-2012, cuyo examen fue recientemente, se han ofertado plazas en todas ellas, excepto de la que nos ocupa en esta editorial, porque obviamente aún no existe Plan Formativo de Enfermero Especialista en Cuidados Médico-Quirúrgicos. Ni lo habrá nunca, me temo. La última propuesta que el Ministerio presentó así lo corrobora: es un plan formativo para una especie de superenfermera/o que debe dominar todo el área de cuidados médico-quirúrgicos dentro de un hospital, algo que es irreal en la actualidad teniendo en cuenta el grado de especialización que las diferentes áreas asistenciales tienen en la actualidad en nuestro sistema sanitario; y porque para eso ya está el enfermero generalista. Según el borrador ministerial vigente, para poder conseguir esta especialidad se propone centrar las rotaciones de las enfermeras en tres grandes áreas capacitación, definidas en este programa como: cuidados periquirúrgicos y peri-intervencionistas, cuidados a pacientes crónicos complejos y cuidados a pacientes críticos y urgencias.

La realidad es evidente y malintencionada con el colectivo: la atención especializada absorbe cerca del 70\% del empleo de enfermería en el Sistema Nacional de Salud español, y por tanto transformar un sistema de enfermeras generalistas ("enfermeras para todo") en un sistema de enfermeras especialistas acarrearía todo un cambio de 
cultura profesional que supondría además de reconocimiento retributivo, estatus y un planteamiento bastante más complejo para los responsables de la gestión de recursos humanos de los hospitales, consejerías de salud, etc. Por tanto, boicotear o utilizar tácticas dilatorias para que no se desarrolle esta especialidad y mucho menos áreas de Capacitación Específica, es una realidad a la que venimos asistiendo desde hace bastantes años los que un día nos ilusionamos con que nuestra actividad diaria tuviera reconocimiento oficial de especialidad. Existen muchos intereses en contra y todos más poderosos que los nuestros. Da igual además, quien gobierne: ha ocurrido siempre lo mismo con administración socialista o popular. Como anécdota, recuerdo el cese de la Ministra Celia Villalobos por parte del Presidente Aznar en 2002, entre otras cuestiones por apoyar incondicionalmente el desarrollo de un decreto de especialidades de enfermería muy generoso con la profesión, lo cual fue desaprobado desde las estructuras profundas del propio ministerio, en parte por esos funcionarios de carrera que ocupan puestos técnicos, que saben hacerse imprescindibles para los políticos de turno, mover los hilos del poder, influir en la dirección que sus intereses o prejuicios les dictan, y finalmente permanecer en sus puestos independientemente de quien gobierne.

La prueba definitiva de que, desde el Ministerio de Sanidad, se tiene claro que esta especialidad no se desarrollará nunca, ha sido la presentación del Proyecto de Real Decreto por el que se regula la Troncalidad y otros aspectos del sistema de Formación sanitaria especializada en Ciencias de la Salud. Se han ignorado totalmente las legítimas aspiraciones de la enfermería de la atención especializada. En este sentido la OCE, ha realizado una valoración general negativa del proyecto por obviar y marginar a la profesión enfermera del contenido del mismo. Asimismo, de conformidad con la propuesta de la Comisión Nacional de la especialidad, propone suprimir la especialidad de Cuidados Médico-Quirúrgicos, y derivado de ese tronco común crear las especialidades de: enfermería de Cuidados Periquirúrgicos y Periintervencionistas, enfermería de Cuidados de Alta Complejidad (oncológico y crónico complejo) y enfermería de Cuidados Críticos y de Riesgo Vital.

En esta misma línea, la Unión Española de Sociedades Científicas de Enfermería (UESCE), de la que la SEDEN forma parte, ha emitido recientemente un comunicado en el que argumenta que la denominación de una especialidad bajo el epígrafe de Médico-Quirúrgica, "no responde, desde el sentido lógico de lo que viene a representar el concepto especialidad, a una necesidad del Sistema Nacional de Salud, en sus estructuras ni por la ordenación y prestación de sus servicios. Tampoco responde, por indefinición derivada de la amplitud del término, a una necesidad de los usuarios o los pacientes; y por supuesto no responde a las necesidades de los profesionales". Por consiguiente la UESCE, solicita la sustitución de la especialidad de enfermería en Cuidados Médico-Quirúrgicos por un nuevo catálogo de especialidades mediante el procedimiento legal y normativo, de acuerdo a las leyes en vigor.

Quien lea esta editorial, supongo que entenderá mi escepticismo, sobre el desarrollo de la especialidad en enfermería nefrológica, desde hace bastante tiempo.

Rodolfo Crespo Montero

Director de Enfermería Nefrológica

El contenido de la revista expresa únicamente la opinión de los autores, que no debe coincidir necesariamente con la de la Sociedad que esta revista representa.

Esta publicación se imprime en papel no ácido. 